\title{
Heart Function and Myocardial Tissue Characterization in Patients with HCV Related Cirrhosis: Diastolic Dysfunction and Cardiac Hypertrophy
}

\author{
Massimo Pozzi ${ }^{*}$,, Daniela Prata Pizzala ${ }^{\mathrm{a}}$, Laura Ratti ${ }^{\mathrm{a}}$, Anna Capra ${ }^{\mathrm{a}}$, Maria Milanese ${ }^{\mathrm{a}}$, \\ Maria Amigoni ${ }^{a}$, Cristina Guidi ${ }^{\mathrm{a}}$, Cristina Giannattasio a and Giuseppe Mancia ${ }^{\mathrm{a}, \mathrm{b}}$ \\ ${ }^{a}$ Clinica Medica, Università Milano-Bicocca, Azienda Ospedaliera San Gerardo, Monza, Milan, Italy \\ ${ }^{b}$ Centro Interuniversitario di Fisiologia Clinica e Ipertensione, Milan, Italy
}

\begin{abstract}
Evidence of diastolic dysfunction in cirrhosis contributed to the definition of cirrhotic cardiomyopathy. In 109 patients with chronic HCV infection with or without cirrhosis E/A ratio, a Doppler marker of diastolic dysfunction, was decreased in cirrhotics $(0.89 \pm 0.03 v s$ controls $1.21 \pm 0.07, \mathrm{p}<0.01)$ and to a lesser extent in patients with advanced liver fibrosis $(1.17 \pm 0.07, \mathrm{p}<0.01)$. Left ventricular parietal wall thickness was increased. The nature of this abnormality in human cirrhosis has not been clarified, animal studies reporting cardiac hypertrophy. To this aim we employed the echocardiographic integrated backscatter (IBS) technique to obtain an indirect estimate of tissue density (decreased when a higher percentage of muscle fibres is present and increased when fibrosis prevails) to provide myocardial tissue characterization in a subset of patients with compensated HCV cirrhosis. The average IBS signal was reduced in cirrhotics at the level of the posterior wall $(21.72 \pm 1.46 \mathrm{~dB}$ versus $30.85 \pm 1.40 \mathrm{~dB}$ in controls, $\mathrm{p}<0.01)$. Our results confirm diastolic dysfunction in postviral cirrhosis pointing to cardiac hypertrophy as the anatomopathological background in the compensated stage of disease.
\end{abstract}

Keywords: Postviral cirrhosis, diastolic dysfunction, echocardiography, integrated backscatter, portal hypertension.

\section{INTRODUCTION}

Cirrhotic cardiomyopathy [1] recently emerged as a novel disease entity to be differentiated from alcoholic heart muscle disease [2]. Hyperdinamic circulation [3], QTc prolongation $[4,5]$, beta-receptors desensitization $[6,7]$, reduced systolic competence under strains [8-11] and diastolic dysfunction [12-17] are the key features of cirrhotic cardiomyopathy. Diastolic dysfunction, characterized by an altered pattern of transmitral flow due to impaired diastolic relaxation of left ventricle, can be easily assessed by echocardiography and accordingly can be considered as a marker of this condition. As far as diastolic dysfunction is concerned, many etiological factors have been reliably advocated as potential pathogenic agents: notably substances as NO [18-21], TNF [22], reactive nitrogen species [23], neurohormones [24-28] may well affect heart structure and function along with circulatory overload $[24,29]$ and overactivity of the SNS [30]. Thickening of heart parietal walls has been reported $[12,14,17,31]$, nevertheless the nature of the structural changes underlying diastolic dysfunction has not been clarified so far. Available literature data are based on animal models [32-34] and on autoptic findings [35] overall handling conflicting results. Given 1) the uncertain nature of the heart structural changes underlying the altered pattern of diastolic function in cirrhosis, 2) the enhanced neurohumoral activity and circulatory derangement characterizing the most advanced stages of cirrhosis when decompensation develops, 3 ) the role of different etiologies of liver diseases, frequently

*Address correspondence to this author at the Clinica Medica, Università Milano-Bicocca, Azienda Ospedaliera San Gerardo, Via Donizetti 106, 20052 Monza, Milan, Italy; Tel: +39 39 2333357; Fax: +39 39 322274;

E-mail: epa.monza@libero.it concomitant in a mixed fashion, and 4) the known cardiotoxic effects of heavy ethanol consumption, the present study was aimed at performing echocardiography with Doppler analysis of transmitral flow to detect diastolic dysfunction and thickening of ventricular parietal walls in a large population of patients with different stages of compensated $\mathrm{HCV}$ related liver disease. Heart tissue characterization by means of echocardiography via the integrated backscatter (IBS) technique was also performed in a subset of cirrhotic patients in an attempt to obtain information on myocardial texture to assess whether hypertrophy or fibrosis is the background morphological change. This technique allows to obtain an indirect estimate of tissue density, usually decreased when a higher percentage of muscle fibres is present and increased when fibrosis prevails $[36,37]$. We also obtained information on the effects of aging on the morphofunctional heart changes observed.

\section{MATERIALS AND METHODOLOGY}

\section{Patients}

The study involved 109 patients (63 males; 46 females) with chronic HCV RNA positive hepatitis with different degrees of liver fibrosis, grouped according to the Ishak staging score as follows:

1. 28 subjects: Ishak 0-2 (18 males, 10 females, mean age $40 \pm 11$ years);

2. 24 subjects: Ishak 3-5 (14 males, 10 females, mean age $53 \pm 8$ years);

3. 57 subjects with preascitic cirrhosis Ishak 6 (31 males, 26 females, mean age $57 \pm 8$ years). All were classified as Child A according to the Child-Pugh score [38]. 
The following exclusion criteria were adopted in patients with liver disease: 1) arterial hypertension, 2) any cardiovascular and lung disease, 3) anemia, 4) creatinine $>1.5 \mathrm{mg} / \mathrm{dL}$, 5) ethanol consumption of any quantity, 6) systemic disease, in particular collagen disorders, autoimmune and endocrine disorders including diabetes, metal overload, 7) any vasoactive drug (including beta-blockers, aldosterone antagonists and diuretics), recent or ongoing treatment with pegylated interferon/ribavirin, 8) cancer, 9) age $>65$ years, 10) Child Class B-C, 11) previous ascites or gastrointestinal bleeding due to portal hypertension.

The following subjects served as controls:

1. 26 healthy normotensive volunteers (15 males, 11 females, mean age $50 \pm 11$ years);

2. 20 patients with idiopathic dilative cardiomyopathy, NYHA II (13 males, 7 females, mean age $60 \pm 11$ years). All subjects tested negative for HCV-RNA.

The study protocol was approved by the Ethics Committee at our institution and all patients gave oral informed consent to participate in the study. A written consent was obtained in patients undergoing portal pressure measurement.

All patients where submitted to a complete echocardiographic examination plus color Doppler analysis.

In a subset of 31 out of 57 cirrhotic patients the IBS analysis was performed. These patients were grouped according to the absence (13 patients, 7 males, 6 females, mean age $58 \pm 8$ years) or presence ( 18 patients, 11 males, 7 females, mean age $56 \pm 11$ years) of indirect signs of portal hypertension. In those displaying indirect signs of portal hypertension (small esophageal varices at endoscopy, dilated portal vein and/or spleen enlargement at ultrasound), hepatic venous pressure gradient ranged from $11 \mathrm{mmHg}$ to 19.5 $\mathrm{mmHg}$ (mean $15 \pm 2.3 \mathrm{mmHg}$ ). 11 healthy subjects (6 males, 5 females, mean age $57 \pm 7$ years) served as controls for IBS analysis.

\section{Methods}

Liver biopsy, as well as upper digestive endoscopy and hepatic venous pressure gradient measurement were performed within 3 months of enrollment. The Ishak staging score ranged from 0 (no liver fibrosis) to 6 (cirrhosis). Serum samples were tested for HCV RNA using nested PCR.

Conventional clinical and biochemistry criteria were adopted to classify cirrhotic subjects according to the ChildPugh score. EKG was normal in all patients with chronic $\mathrm{HCV}$ infection. All patients with idiopathic dilated cardiomyopathy were in synus rhythm. Cardioactive drugs, including diuretics and aldosterone antagonists, were allowed in this group.

In cirrhotic subjects with indirect signs of portal hypertension at ultrasound portal pressure measurement was obtained by hepatic vein catheterization as previously reported [28]. Briefly, a $8 \mathrm{~F}$ venous introducer (Cordis Corporation, Miami, USA) was inserted in the right jugular vein under local anesthesia: then a 7F balloon catheter (Meditech, Boston Scientific Corporation, Waterton, USA) was used for measurements. Hepatic venous pressure measurement was obtained by means of a pressure recorder (Boston Scientific, Model 8300, Signal Acquisition Module, Menlo Park, CA,
USA) in the occluded position and then after deflation of the balloon in the free position [39]. The hepatic venous pressure gradient was calculated as the difference between the occluded and the free hepatic venous pressure. Average data were the means of 3 measurements.

Each standard cardiac ultrasound examination was performed in the morning in a quiet room.

Echocardiographic (Sonos 7500, Philips, Bothell, Washington DC, USA) recordings were obtained by a $2.5 \mathrm{MHz}$ probe in the left parasternal view and the apical four-chamber view measuring diameters and volumes of cardiac chambers according to the American Society of Echocardiography Guidelines [40, 41]. In the apical four-chamber view a Doppler recording of diastolic mitral flow was obtained by positioning the sample volume at the level of the mitral valve leaflets ( $\mathrm{E}$ wave, A wave, deceleration time of $\mathrm{E}$ wave) and at midway between the left ventricular outflow tract and mitral valve leaflet. Measurements derived from at least 3 cardiac cycles were averaged. Systolic function was evaluated by the ejection fraction of the left ventricle (monoplane Simpson method) [42]. The echocardiographic variables assessed in the present study included left ventricular end diastolic diameter, interventricular septum and posterior wall thickness at diastole and their sum (left ventricle wall thickness, LVWt). The Doppler method provides a beat-to-beat non invasive assessment of ventricular filling. This is subdivided into the peak filling velocity during early ventricle diastole (E wave) and the filling velocity during atrial systole (A wave). The E wave-to-A wave ratio (E/A ratio) represents an index of diastolic function. Other parameters of diastolic function included deceleration time (Dec $t$ ) of the $\mathrm{E}$ wave and isovolumic relaxation time (IVRt). Dec $t$ is expressed as the time needed to equalize pressures between left atrium and ventricle: an increase of Dec $t$ indicates a reduction in ventricular relaxation because of an increased stiffness of ventricular muscle and impaired decay of left ventricular pressure during diastole. IVRt was measured positioning the Doppler sample volume towards the outflow tract of the left ventricle and it expresses the left ventricle isovolumic filling time (i.e. the interval from the closure of the aortic valve to the opening of the mitral valve). This index increases when ventricular relaxation is impaired. Images were stored on a digital support. Analysis was blindly performed in triplicate by the same reader unaware of the stage of liver disease. The within-reader coefficient of variability of the measured parameters amounts to $3 \%$.

\section{Integrated Backscatter}

This is an ultrasonographic investigation that may help to analyze the texture of myocardial tissue in different pathological conditions. Ultrasound tissue characterization is based on tissue acoustic impedance, which is the product of velocity of diffusion within the tissue and tissue density itself. The phenomenon of ultrasound reflectivity is linked to the non homogeneity of acoustic impedance. This distinct property of each tissue leads to different patterns of refraction of ultrasonic waves when they cross the boundary between different tissues or areas of the same tissue displaying different acoustic impedances. When the wavelength is smaller than the magnitude of the border region, the reflection produced is called specular and is substantially unidirectional. On the contrary, when the boundary is smaller than the wavelength of the ultrasonic incident beam, reflection 
spreads in a multidirectional fashion (scattering). Within the multidirectional waves, those moving back towards the transducer (those which can be analyzed) are actually "backscattered". The integrated backscatter is a relative measure of a total ultrasonic energy that is backdispersed from a small volume of tissue sampled. The knowledge of the scattering pattern of the myocardial tissue is the main hint for the clinical applications of ultrasound tissue characterization. Intensity of scattering relies on the shape, dimension and concentration of the elements to be investigated (sarcomers or myocite, vessels, matrix).

Acquisition of the backscatter signal is performed during the whole cardiac cycle.

Data obtained in backscatter are quantified in a logarithmic scale in decibels $(\mathrm{dB})$ with a range from 0 to $60 \mathrm{~dB}$. Data derive from a specific region of interest (ROI).

Two types of informations can be achieved:

1. Average image intensity (Aii): represents the mean value of intensity assessed in decibels. Tissues with prevalent fibrotic component have greater mean density while tissue with higher content of elastin or muscle fibres have lower mean density if compared to a reference, i.e. blood.

2. Cyclic variation of echodensity (peak-to-peak intensity, PPI or CV IBS): is an index that measures the cyclic variation (systodiastolic) of the IBS signal, mainly linked to the intrinsic contractility of myocardium. Cyclic variation is mainly dependent on the anisotropism of myocardial fibres: since orientation of fibres changes along with myocardial contraction, ultrasonic properties change according to the angle of incidence between the ultrasonic beam and the sample tissue.

To perform the backscatter tissue characterization we have used a dedicated software for the analysis in IBS mode.
Image acquisition in IBS has been obtained by the long axis parasternal view at the level of the mean portion of the interventricular septum. In this projection the ultrasonic beam is perpendicular to the main disposition of the myocardial fibres.

Once acquired in real time, IBS images are thereafter offline analyzed sampling one region of interest (ROI) of $31 \mathrm{x}$ 31 pixel of ellissoidal shape at the level of the mean portion of the interventricular septum and of the posterior wall of the left ventricle.

The location of the ROI is then frame by frame manually adjusted so that echoes arising from epicardic and endocardic structures are not included. During the analysis, for each frame the mean IBS values for each ROI is calculated and expressed in decibels (Aii) and the cyclic variation of IBS (CV- IBS) or PPI (peak-to-peak intensity). The latter corresponds to the ranging of the curve time-intensity calculated considering within one cycle those four consecutive frames with the highest IBS (diastolic frames) and those with the lowest IBS (systolic frames) values. From these values the differences are calculated, indicating the cyclic variation of IBS.

Time and lateral gain compensation were kept constant during the analysis as well as depth of acquisition and gain $(80 \mathrm{~dB})$.

\section{Data Analysis}

Statistical analysis was performed with the SPSS package. Results are expressed as means \pm SEM. Student's $t$ test was used for the comparison of variables. The Bonferroni correction was employed for multiple comparisons, when applicable. Statistical significance was established at $\mathrm{p}<.05$

\section{RESULTS}

Table 1 summarizes demographics and the results of echocardiographic variables in control subjects, in the three

Table 1. Demographic and Echocardiographic Variables

\begin{tabular}{|c|c|c|c|c|c|}
\hline & Control & Liver Fibrosis(Ishak Score 0-2) & Liver Fibrosis(Ishak Score 3-5) & Cirrhosis & $\begin{array}{l}\text { Idiopathic Dilated } \\
\text { Cardiomyopathy }\end{array}$ \\
\hline $\begin{array}{c}\text { Patients }(\mathrm{n}) \\
\text { AGE }(\text { years, } \pm \text { SD) }\end{array}$ & $\begin{array}{c}26 \\
50 \pm 11\end{array}$ & $\begin{array}{c}28 \\
40 \pm 11\end{array}$ & $\begin{array}{c}24 \\
53 \pm 8\end{array}$ & $\begin{array}{c}57 \\
57 \pm 8\end{array}$ & $\begin{array}{c}20 \\
60 \pm 11\end{array}$ \\
\hline $\operatorname{BSA}\left(\mathrm{m}^{2}\right)$ & $1.68 \pm 0.03$ & $1.79 \pm 0.07$ & $1.86 \pm 0.04$ & $1.81 \pm 0.02$ & $1.80 \pm 0.05$ \\
\hline LVEF (\%) & $66 \pm 0.01$ & $68 \pm 0.01$ & $69 \pm 0.01$ & $67 \pm 0.01$ & $35 \pm 0.01$ \\
\hline $\operatorname{LVDd}(\mathrm{cm})$ & $4.79 \pm 0.10$ & $4.81 \pm 0.08$ & $5.02 \pm 0.09$ & $4.91 \pm 0.07$ & $5.98 \pm 0.24$ \\
\hline LVDs $(\mathrm{cm})$ & $3.33 \pm 0.16$ & $3.49 \pm 0.11$ & $3.35 \pm 0.11$ & $3.06 \pm 0.08$ & $4.68 \pm 0.30$ \\
\hline IVSs $(\mathrm{cm})$ & $1.42 \pm 0.04$ & $1.41 \pm 0.04$ & $1.51 \pm 0.04$ & $1.48 \pm 0.03$ & $1.15 \pm 0.06$ \\
\hline IVSd $(\mathrm{cm})$ & $0.94 \pm 0.03$ & $0.94 \pm 0.05$ & $1.02 \pm 0.03$ & $1.12 \pm 0.02$ & $0.98 \pm 0.05$ \\
\hline LVPWd $(\mathrm{cm})$ & $0.86 \pm 0.03$ & $0.86 \pm 0.03$ & $0.94 \pm 0.03$ & $0.93 \pm 0.02$ & $0.83 \pm 0.04$ \\
\hline LVWt $(\mathrm{cm})$ & $1.79 \pm 0.06$ & $1.79 \pm 0.04$ & $1.96 \pm 0.06$ & $2.04 \pm 0.03$ & $1.82 \pm 0.07$ \\
\hline $\mathrm{E} / \mathrm{A}$ ratio & $1.21 \pm 0.07$ & $1.31 \pm 0.06$ & $1.17 \pm 0.07$ & $0.89 \pm 0.03$ & $0.72 \pm 0.06$ \\
\hline IVRt (ms) & $88.78 \pm 2.37$ & $85.60 \pm 4.84$ & $87.56 \pm 4.46$ & $107.81 \pm 3.66$ & $90.31 \pm 2.78$ \\
\hline $\mathrm{DECt}(\mathrm{ms})$ & $194.23 \pm 8.09$ & $194.88 \pm 8.87$ & $206.32 \pm 9.90$ & $266.12 \pm 7.58$ & $226.50 \pm 16.29$ \\
\hline
\end{tabular}

Legend Abbreviations: BSA, body surface area; LVEF, left ventricular ejection fraction; LVDd, left ventricular diastolic diameter; LVDs, left ventricular systolic diameter; IVSs, interventricular septum in systole; IVSd, interventricular septum in diastole; LVPWd, left ventricular posterior wall in diastole; LVWt, left ventricular wall thickness; E/A ratio, ratio of the early peak to the late peak filling velocities; IVRt, isovolumic relaxation time; DECt, deceleration time of peak E velocity.

Results are presented as mean $\pm \mathrm{SEM}$. 


\section{LVEF}

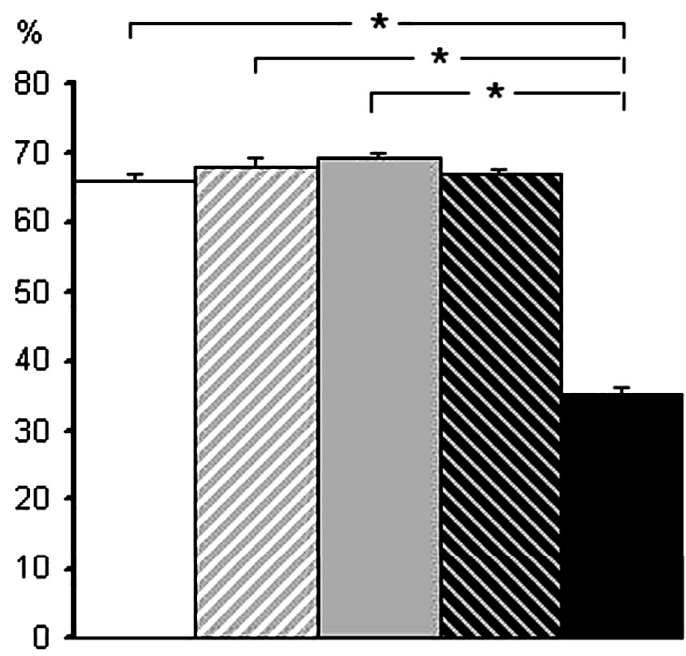

LWht

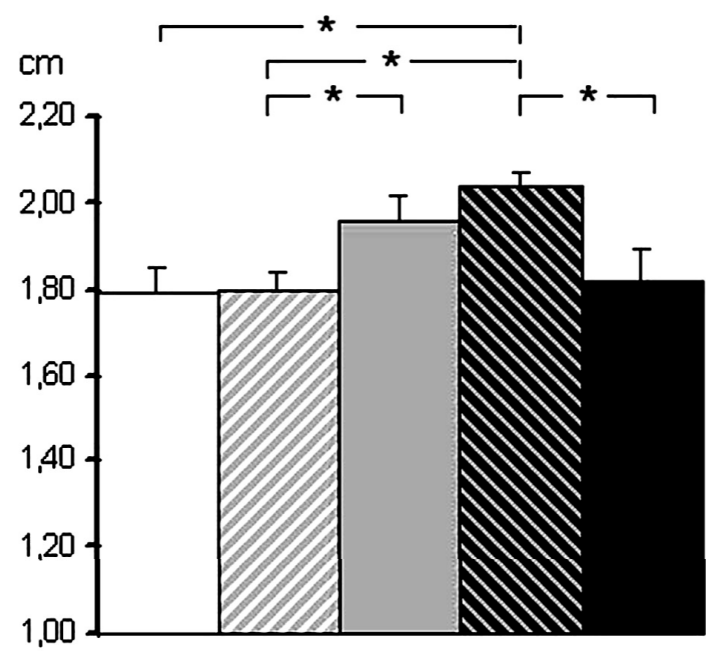

Fig. (1). Echocardiographic variables in normal subjects $\square$, in patients with mild liver fibrosis (Ishak score 0-2) $\square$, in patients with advanced liver fibrosis (Ishak score 3-5) $\square$, in cirrhotic patients $\mathbf{N}$ and in patients with idiopathic dilated cardiomyopathy $\mathbf{\square}$. LVEF, left ventricular ejection fraction; LVWt, left ventricular wall thickness. Results are presented as mean $\pm \mathrm{SEM} .{ }^{*} \mathrm{p}<0.01$.

groups of patients with different stages of liver disease and in the group of patients with heart disease.

Ejection fraction is consistently reduced in the latter group, whereas normal values are observed in each group of patients with liver disease irrespective of disease stage (Fig. 1, left panel).

Table 1 also shows the values of left ventricle parietal wall thickness (obtained as the sum of thickness of posterior wall of left ventricle and interventricular septum, LVPWd + IVSd). Values observed in control group and patients with heart disease are superimposable and significantly different from those observed in patients with advanced liver fibrosis and cirrhosis (Fig. 1, right panel) in whom an increase is actually observed paralleling progression of disease stage.
In patients with liver disease diastolic function is significantly impaired only in patients with cirrhosis and superimposable to that observed in patients with heart disease. This is particularly the case for E/A ratio, IVRT and to a lesser extent for Dec T (Fig. 2).

Table 2 summarizes demographics, portal hemodinamycs, IBS data of the subset of patients with cirrhosis.

Mean values of IBS (Aii) are overall significantly reduced as compared to controls either when sampled at the level of the posterior wall (PP, Fig. 3, left panel) and of the interventricular septum (IVS, Fig. 3, right panel). No significant differences were observed between patients with clinically significant portal hypertension and those without, taking into account the relatively limited number of patients
E/A ratio

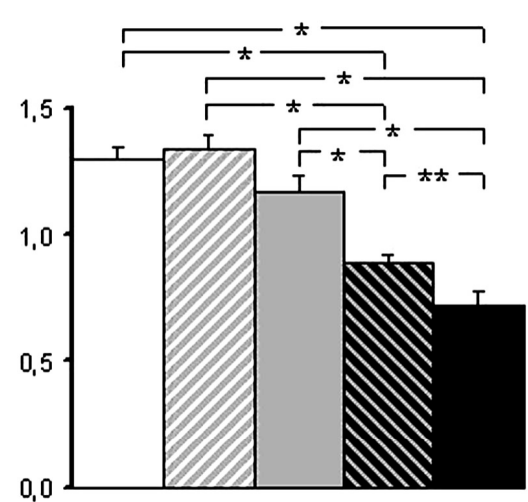

IVRt

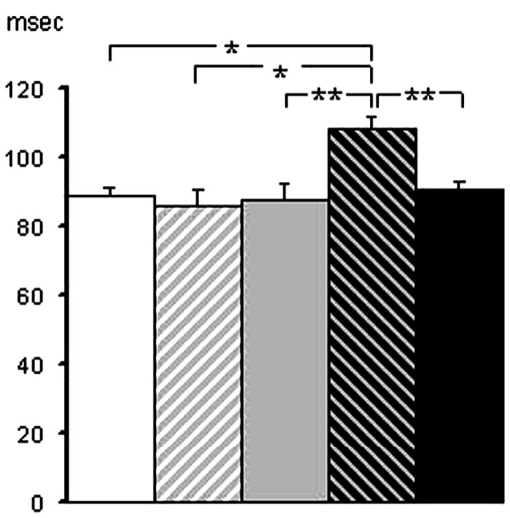

DECt

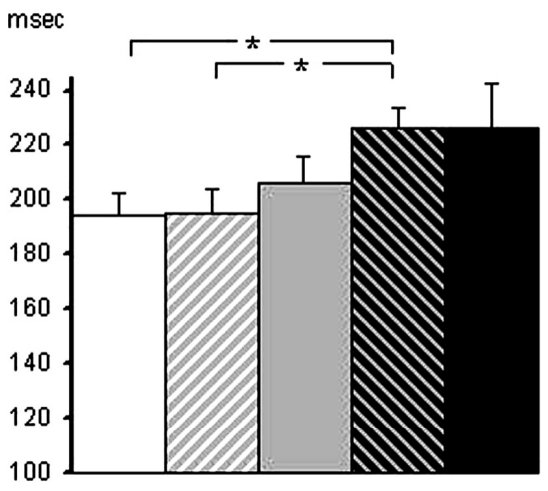

Fig. (2). Left ventricular diastolic function in normal subjects $\square$, in patients with mild liver fibrosis (Ishak score 0-2) 7 , in patients with advanced liver fibrosis (Ishak score 3-5) , in cirrhotic patients $\mathbf{N}$ and in patients with Idiopathic dilated cardiomyopathy $\mathbf{Q}$. E/A ratio, ratio of the early peak to the late peak filling velocities; IVRt, isovolumic relaxation time; DECt, deceleration time of peak E velocity. Results are presented as mean \pm SEM. ${ }^{*} \mathrm{p}<0.01, * * \mathrm{p}<0.05$. 
Table 2. Demographic, Portal Hemodynamics, Integrated Backscatter Data

\begin{tabular}{|c|c|c|c|c|}
\hline & Control & Cirrhosis & Cirrhosis without Portal Hypertension & Cirrhosis with Portal Hypertension \\
\hline \hline Patients (n) & 11 & 31 & 13 & 18 \\
\hline AGE (years, \pm SD) & $57 \pm 7$ & $57 \pm 9$ & $58 \pm 8$ & $56 \pm 11$ \\
\hline HVPG (mmHg) & N.A. & - & N.A. & $15 \pm 0.64$ \\
\hline PW-PPI (dB) & $11.49 \pm 1.18$ & $12.49 \pm 0.74$ & $11.07 \pm 0.49$ & $13.50 \pm 0.85$ \\
\hline PW-aii (dB) & $30.85 \pm 1.40$ & $21.72 \pm 1.46$ & $22.01 \pm 1.77$ & $21.52 \pm 1.24$ \\
\hline IVS-PPI (dB) & $10.99 \pm 1.29$ & $11.51 \pm 0.61$ & $11.78 \pm 0.56$ & $11.32 \pm 0.66$ \\
\hline IVS-aii (dB) & $29.96 \pm 1.61$ & $23.78 \pm 1.11$ & $23.96 \pm 1.42$ & $23.65 \pm 0.89$ \\
\hline
\end{tabular}

Legend Abbreviations: HVPG, hepatic venous pressure gradient; PW-PPI, peak-to-peak IBS intensity of the posterior wall; PW-aii, average myocardial IBS intensity of the posterior wall; IVS-PPI, peak-to-peak IBS intensity of the interventricular septum; IVS-aii, average myocardial IBS intensity of the interventricular septum; N.A., not available.

Results are presented as mean \pm SEM.

considered. These findings seem to suggest the presence of hypertrophy versus fibrosis of myocardial tissue.

Finally, considering the aging-related reduction of E/A (presbycardia) in normal subjects, data on diastolic function of our patients with liver fibrosis and cirrhosis have been grouped according to age compared to the mean values reported in the large series of normal subjects by Benjamin et al. in the Framingham study [43]. As shown in Fig. (4) E/A ratio values are overall reduced in patients with cirrhosis irrespective of age. In subjects with liver fibrosis a slight reduction of E/A ratio is observed only in the fourth decade, values being superimposable in the later decades.

\section{DISCUSSION}

The concept of diastolic dysfunction implies a change in the myocardial properties that impairs the capability of the ventricular cavity to accept an adequate diastolic volume at rest and during exercise, despite normal filling pressures. During diastole, "ventricular suction" resulting from the active elastic recoil of the myocardium, leads to rapid ventricular filling during early diastole. Reduction of ventricular recoil properties induces stagnation of blood in left atrium and thus in pulmonary capillaries. Therefore, the trans-mitral pressure gradient is increased, and the atrial contribution to ventricular filling increases in an attempt to restore an adequate left ventricular diastolic volume. Echocardiography allows easy identification of diastolic dysfunction by conventional parameters like $\mathrm{E} / \mathrm{A}$ ratio, deceleration time of $\mathrm{E}$ wave and isovolumic relaxation time. Reduced left ventricular distensibility is frequently a contributing factor to left ventricular diastolic dysfunction [43-45]. The possible mechanisms of impaired relaxation include increased parietal wall thickness likely due to hypertrophy and/or fibrosis [46, 47].

Examples of clinical conditions that typically have prolonged ventricular relaxation include normal aging process (presbycardia), ischemia, myocardial fibrosis, diabetic cardiomyopathy, connective tissue disorders and concentric left ventricular hypertrophy [45]. In the last few years, evidence is accumulating that diastolic dysfunction also occurs in cirrhosis, irrespective of alcoholic or non-alcoholic etiology $[12-14,17,31]$. This is part of a spectrum of cardiac abnormalities observed in liver cirrhosis, termed cirrhotic cardiomyopathy [1].
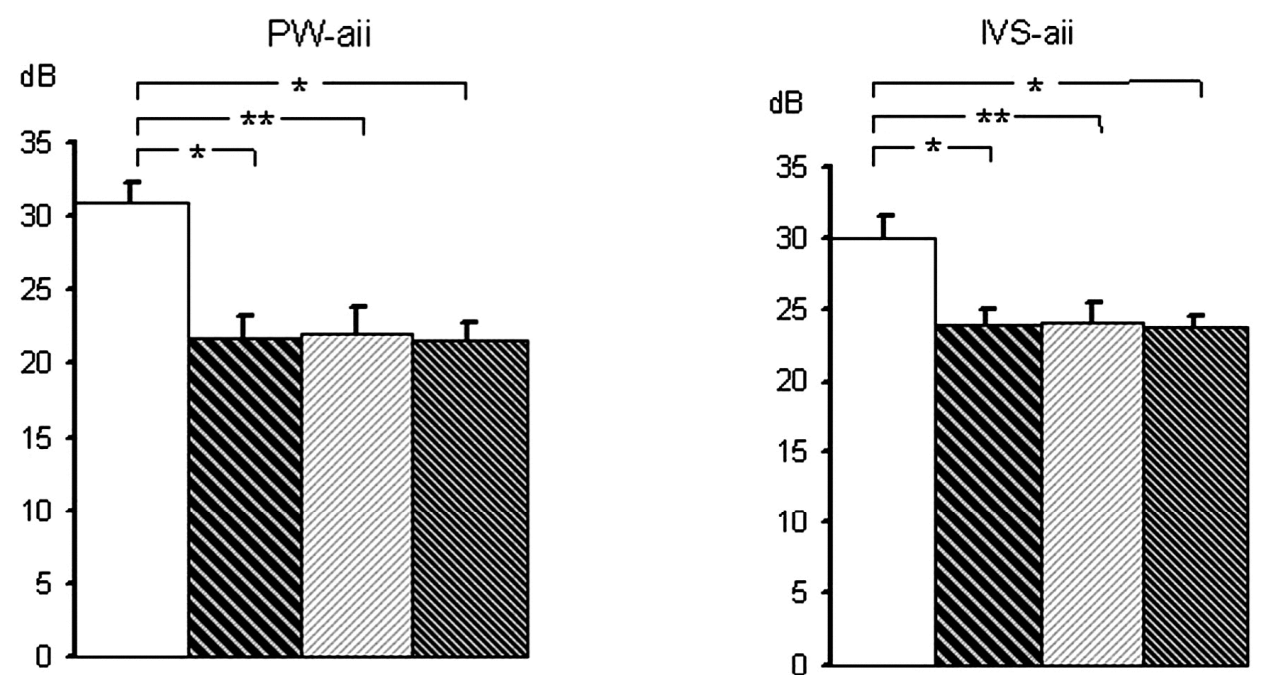

Fig. (3). Ultrasound tissue characterization in normal subjects $\square$, in the whole gruop of cirrhotic patients $\mathbf{N}$, in the subset of cirrhotic patients without portal hypertension $/ 2$ and in the subset of cirrhotic patients with portal hypertension (mean HVPG: $15 \mathrm{mmHg}) \mathbb{N}$. PW-aii, average myocardial IBS (Integrated Backscatter) intensity of the posterior wall; IVS-aii, average myocardial IBS (Integrated Backscatter) intensity of the interventricular septum. Results are presented as mean $\pm \mathrm{SEM}$. ${ }^{*} \mathrm{p}<0.01,{ }^{* *} \mathrm{p}<0.05$. 
E/A

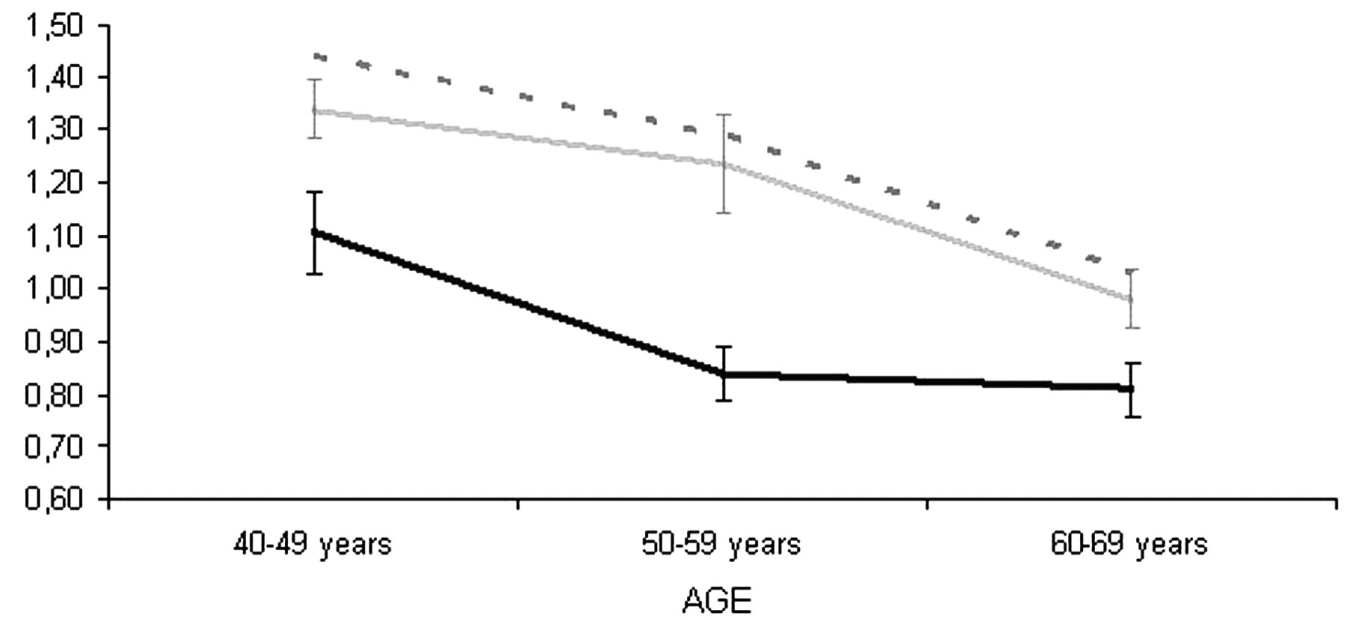

Fig. (4). Age-related reduction of E/A ratio in normal subjects (historical comparison with the mean values reported by Benjamin et al. in the

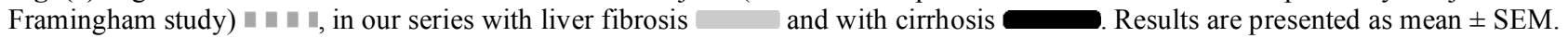

This alteration is more marked in presence of ascites, presumably because the increased intrathoracic pressure and the bulging of the diaphragm, induced by abdominal fluid accumulation, interfere with the diastolic expansion of the ventricles [15]. It is present, however, even in absence of ascites, suggesting that non-mechanical factors are involved as well $[12,3]$.

Actually, most previous studies have investigated patients with mixed etiologies of liver disease $[13,14]$ introducing a bias in the interpretation of results according to the known potential interference of various exogenous factors and pathologic conditions on cardiovascular variables. Nevertheless diastolic dysfunction has been reported even in patients with idiopathic (non cirrhotic) portal hypertension [16], pointing to the role of hemodynamic derangement characterizing advanced cirrhosis $[24,29]$ as the leading factor. Facing these consideration our study was devoted to examine a large series of subjects in whom any factor other than $\mathrm{HCV}$ was involved and disease stage was assessed by liver biopsy, excluding patients with far advanced disease.

Our findings in this selected population further corroborate previous findings by other authors [13-15] and by our group [12], indicating that diastolic dysfunction is an expression of cardiac involvement paralleling progression of cirrhosis. Indeed our data, based on the historical comparison with the Framingham study [43] suggest that age, one of the components involved in the pathogenesis of diastolic dysfunction and possibly a misleading issue in previous investigations, can be excluded at least as a co-factor.

Previous studies have identified structural change of the heart in cirrhotic subjects and postulated its role as the anatomic background of impaired transmitral flow [14, 28]. Nevertheless in vivo studies of myocardial tissue characterization in compensated cirrhosis are substantially lacking so far.

Indeed, early autopsy studies have reported that cirrhosis is accompanied by cardiac abnormalities such as myocardial hypertrophy, cardiomyocyte edema, fibrosis, nuclear vacuo- lation and exudation. Most of these observations were obtained in patients with alcoholic cirrhosis and it was naturally inferred that the cardiac abnormalities were due to latent or overt alcoholic cardiomyopathy. Lunseth et al. [35] in this study curiously reported cardiac hypertrophy to be more evident in early to moderate stages of cirrhosis.

Recently Pozzi et al. [28] confirmed these findings in a human study highlighting a potential protective role of chronic aldosterone blockade currently employed in decompensated cirrhosis. Nevertheless, autoptic findings notably are biased by the nature of the events that lead to death cirrhotic subjects: circumstances like sepsis, shock and hepatorenal syndrome may have a severe impact on cardiac function [22] besides post-mortem heart tissue changes.

Since the major abnormality leading to diastolic dysfunction in cirrhosis appears to be increased cardiac stiffness, the nature of this change deserves a definition. In a recent experimental study Inserte et al. [32] described eccentric left ventricular hypertrophy in the hearts of rats in which portal hypertension was induced by common bile duct ligation. By heart weight assessment, morphometric and histomorphometric analysis they observed significantly heavier hearts, with increased left ventricle wall thickness and cardiomyocyte width and length in these animals as compared to sham operated controls, without any increase in interstitial collagen. They concluded that the lack of fibrosis and the absence of up-regulation of TGF-beta1, a marker of angiotensin-II induced myocardial hypertrophy [48], point to mechanical overload as the leading factor with a minor role for neuroendocrine overactivity.

Indeed in human cirrhosis, myocardial hypertrophy could be an adaptive response to chronically expanded blood volume, since these patients have sodium and water retention, starting at the pre-ascitic stage of the disease [24, 49]: notably at this early stage neuroendocrine overactivity is slight, becoming increasingly more severe as the cirrhotic process progresses [30]. Nevertheless, in previous studies sympathetic nerve outflow has been documented to be already in- 
creased even in the compensated stage of disease [50, 51]: then the sympathetic nervous system could play a key role in the development of left ventricular hypertrophy in cirrhosis, as already clearly reported in hypertension [52].

In contrast, abnormal collagen accumulation due to an enhanced collagen synthesis by heart fibroblasts, could occur in later stages when hemodynamic derangement is accompanied by a huge homeostatic counterregulatory release of neurohumoral substances overall affecting cardiac structure and heart remodelling in an additive fashion.

Quantitative myocardial tissue characterization is being developed as an adjunct to conventional echocardiography to delineate the physical state of myocardium under diverse pathophysiological states [53], enhancing our ability to assess myocardial function non-invasively. Real-time quantitative integrated backscatter imaging has made possible clinical investigations in patients with ischemic heart disease [54], hypertrophic cardiomyopathy [36, 55], among others. Published studies suggest that IBS is overall reduced in presence of cardiac hypertrophy [56] whereas an increase in IBS signal accounts for fibrosis [57].

We applied this method in an attempt to characterize myocardial structure in patients with post viral compensated cirrhosis, heart histological sampling being risky and accordingly not ethically acceptable in this clinical context.

Our findings of reduced IBS in our series are in agreement with experimental data published by Inserte et al. [32] and are consistent with the presence of cardiac hypertrophy: structural myocardial abnormalities likely contribute to abnormal left ventricular filling in compensated cirrhosis as observed in hypertension [53]. A fibrotic reaction cannot be excluded but we can postulate that this ensues in the later stages of disease.

Finally, a putative role of HCV infection as a pathogenic agent should be considered. Indeed few studies have shown a prevalence of HCV infection in subjects with hypertrophic cardiomyopathy $[58,59]$ but not in those with idiopathic dilating cardiomyopathy $[60,61]$. Moreover, Yan et al. have recently shown in an autoptic study the presence of active $\mathrm{HCV}$ replication in the heart of cirrhotic patients [62]. These reports need further investigations devoted to better clarify the effects of HCV on extrahepatic tissues and in particular the myocardial tissue.

\section{CONCLUSIONS}

In conclusion the results of our study provide new clues in the understanding of the complexity of cirrhotic cardiomyopathy confirming 1) the presence of diastolic dysfunction and suggesting 2) hypertrophy as the structural myocardial abnormality producing diastolic dysfunction in a large and selected series of patients with post viral compensated cirrhosis. These findings also introduce new considerations on the potential role of drugs such as beta blockers, angiotensin II receptor antagonists and aldosterone antagonists: their therapeutic application in earlier stages of the cirrhotic disease might prove useful in the clinical management of cirrhotic cardiomyopathy before decompensation of disease develops [63-65].

\section{REFERENCES}

[1] Ma Z, Lee SS. Cirrhotic cardiomyopathy: getting to the heart of the matter. Hepatology 1996; 24(2): 451-9.

[2] Piano MR. Alcoholic cardiomyopathy: incidence, clinical characteristics, and pathophysiology. Chest 2002; 121(5): 1638-50.

[3] Abelmann WH. Hyperdynamic circulation in cirrhosis: a historical perspective. Hepatology 1994; 20(5): 1356-8.

[4] Bernardi M, Calandra S, Colantoni A, et al. Q-T interval prolongation in cirrhosis: prevalence, relationship with severity, and etiology of the disease and possible pathogenetic factors. Hepatology 1998; 27(1): 28-34.

[5] Henriksen JH, Fuglsang S, Bendtsen F, Christensen E, Moller S. Dyssynchronous electrical and mechanical systole in patients with cirrhosis. J Hepatol 2002; 36(4): 513-20.

[6] Lee SS, Marty J, Mantz J, Samain E, Braillon A, Lebrec D. Desensitization of myocardial beta-adrenergic receptors in cirrhotic rats. Hepatology 1990; 12(3 Pt 1): 481-5.

[7] Gerbes AL, Remien J, Jungst D, Sauerbruch T, Paumgartner G. Evidence for down-regulation of beta-2-adrenoceptors in cirrhotic patients with severe ascites. Lancet 1986; 1(8495): 1409-11.

[8] Lunzer MR, Newman SP, Bernard AG, Manghani KK, Sherlock SP, Ginsburg J. Impaired cardiovascular responsiveness in liver disease. Lancet 1975; 2(7931): 382-5.

[9] Grose RD, Nolan J, Dillon JF, et al. Exercise-induced left ventricular dysfunction in alcoholic and non-alcoholic cirrhosis. J Hepatol 1995; 22(3): 326-32.

[10] Wong F, Girgrah N, Graba J, Allidina Y, Liu P, Blendis L. The cardiac response to exercise in cirrhosis. Gut 2001; 49(2): 268-75.

[11] Bernardi M, Rubboli A, Trevisani F, et al. Reduced cardiovascular responsiveness to exercise-induced sympathoadrenergic stimulation in patients with cirrhosis. J Hepatol 1991; 12(2): 207-16.

[12] Pozzi M, Carugo S, Boari G, et al. Evidence of functional and structural cardiac abnormalities in cirrhotic patients with and without ascites. Hepatology 1997; 26(5): 1131-7.

[13] Finucci G, Desideri A, Sacerdoti D, et al. Left ventricular diastolic function in liver cirrhosis. Scand J Gastroenterol 1996; 31(3): 27984.

[14] Wong F, Liu P, Lilly L, Bomzon A, Blendis L. Role of cardiac structural and functional abnormalities in the pathogenesis of hyperdynamic circulation and renal sodium retention in cirrhosis. Clin Sci (Lond) 1999; 97(3): 259-67.

[15] Valeriano V, Funaro S, Lionetti R, et al. Modification of cardiac function in cirrhotic patients with and without ascites. Am J Gastroenterol 2000; 95(11): 3200-5.

[16] De BK, Majumdar D, Das D, et al. Cardiac dysfunction in portal hypertension among patients with cirrhosis and non-cirrhotic portal fibrosis. J Hepatol 2003; 39(3): 315-9.

[17] Pozzi M, Redaelli E, Ratti L, et al. Time-course of diastolic dysfunction in different stages of chronic HCV related liver diseases. Minerva Gastroenterol Dietol 2005; 51(2): 179-86.

[18] Vallance P, Moncada S. Hyperdynamic circulation in cirrhosis: a role for nitric oxide? Lancet 1991; 337(8744): 776-8.

[19] van Obbergh L, Vallieres Y, Blaise G. Cardiac modifications occurring in the ascitic rat with biliary cirrhosis are nitric oxide related. J Hepatol 1996; 24(6): 747-52.

[20] Pizcueta MP, Pique JM, Bosch J, Whittle BJ, Moncada S. Effects of inhibiting nitric oxide biosynthesis on the systemic and splanchnic circulation of rats with portal hypertension. Br J Pharmacol 1992; 105(1): 184-90.

[21] La Villa G, Barletta G, Pantaleo P, et al. Hemodynamic, renal, and endocrine effects of acute inhibition of nitric oxide synthase in compensated cirrhosis. Hepatology 2001; 34(1): 19-27.

[22] Ruiz-del-Arbol L, Urman J, Fernandez J, et al. Systemic, renal, and hepatic hemodynamic derangement in cirrhotic patients with spontaneous bacterial peritonitis. Hepatology 2003; 38(5): 1210-8.

[23] Ottesen LH, Harry D, Frost M, et al. Increased formation of Snitrothiols and nitrotyrosine in cirrhotic rats during endotoxemia. Free Radic Biol Med 2001; 31(6): 790-8.

[24] Schrier RW, Arroyo V, Bernardi M, Epstein M, Henriksen JH, Rodes J. Peripheral arterial vasodilation hypothesis: a proposal for the initiation of renal sodium and water retention in cirrhosis. Hepatology 1988; 8(5): 1151-7.

[25] Housset C. The dual play of endothelin receptors in hepatic vasoregulation. Hepatology 2000; 31(4): 1025-6.

[26] Leivas A, Jimenez W, Bruix J, et al. Gene expression of endothelin-1 and ET(A) and ET(B) receptors in human cirrhosis: rela- 
tionship with hepatic hemodynamics. J Vasc Res 1998; 35(3): 18693.

[27] Nicholls KM, Shapiro MD, Van Putten VJ, et al. Elevated plasma norepinephrine concentrations in decompensated cirrhosis. Association with increased secretion rates, normal clearance rates, and suppressibility by central blood volume expansion. Circ Res 1985; 56(3): 457-61.

[28] Pozzi M, Grassi G, Ratti L, et al. Cardiac, neuroadrenergic, and portal hemodynamic effects of prolonged aldosterone blockade in postviral child A cirrhosis. Am J Gastroenterol 2005; 100(5): 11106.

[29] Schrier RW, Ecder T. Gibbs memorial lecture. Unifying hypothesis of body fluid volume regulation: implications for cardiac failure and cirrhosis. Mt Sinai J Med 2001; 68(6): 350-61.

[30] Henriksen JH, Moller S, Ring-Larsen H, Christensen NJ. The sympathetic nervous system in liver disease. J Hepatol 1998; 29(2): 328-41.

[31] La Villa G, Barletta G, Romanelli RG, et al. Cardiovascular effects of canrenone in patients with preascitic cirrhosis. Hepatology 2002; 35(6): 1441-8

[32] Inserte J, Perello A, Agullo L, et al. Left ventricular hypertrophy in rats with biliary cirrhosis. Hepatology 2003; 38(3): 589-98.

[33] Ma Z, Lee SS, Meddings JB. Effects of altered cardiac membrane fluidity on beta-adrenergic receptor signalling in rats with cirrhotic cardiomyopathy. J Hepatol 1997; 26(4): 904-12.

[34] Battarbee HD, Zavecz JH. Cardiac performance in the portal veinstenosed rat. Am J Physiol 1992; 263(2 Pt 1): G181-G185.

[35] Lunseth JH, Olmstead EG, Abboud F. A study of heart disease in one hundred eight hospitalized patients dying with portal cirrhosis. AMA Arch Intern Med 1958; 102(3): 405-13.

[36] Masuyama T, Nellessen U, Schnittger I, Tye TL, Haskell WL, Popp RL. Ultrasonic tissue characterization with a real time integrated backscatter imaging system in normal and aging human hearts. J Am Coll Cardiol 1989; 14(7): 1702-8.

[37] Picano E, Pelosi G, Marzilli M, et al. In vivo quantitative ultrasonic evaluation of myocardial fibrosis in humans. Circulation 1990; 81(1): 58-64.

[38] Pugh RN, Murray-Lyon IM, Dawson JL, Pietroni MC, Williams R. Transection of the oesophagus for bleeding oesophageal varices. $\mathrm{Br}$ J Surg 1973; 60(8): 646-9.

[39] Groszmann RJ, Wongcharatrawee S. The hepatic venous pressure gradient: anything worth doing should be done right. Hepatology 2004; 39(2): 280-2.

[40] Sahn DJ, DeMaria A, Kisslo J, Weyman A. Recommendations regarding quantitation in M-mode echocardiography: results of a survey of echocardiographic measurements. Circulation 1978; 58(6): 1072-83.

[41] Henry WL, DeMaria A, Gramiak R, et al. Report of the American Society of Echocardiography Committee on Nomenclature and Standards in Two-dimensional Echocardiography. Circulation 1980; 62(2): 212-7.

[42] Quinones MA, Douglas PS, Foster E, et al. ACC/AHA clinical competence statement on echocardiography: a report of the American College of Cardiology/American Heart Association/American College of Physicians-American Society of Internal Medicine Task Force on clinical competence. J Am Soc Echocardiogr 2003; 16(4): 379-402.

[43] Benjamin EJ, Levy D, Anderson KM, et al. Determinants of Doppler indexes of left ventricular diastolic function in normal subjects (the Framingham Heart Study). Am J Cardiol 1992; 70(4): 508-15.

[44] Nishimura RA, Tajik AJ. Evaluation of diastolic filling of left ventricle in health and disease: Doppler echocardiography is the clinician's Rosetta Stone. J Am Coll Cardiol 1997; 30(1): 8-18.

[45] Vasan RS, Levy D. Defining diastolic heart failure: a call for standardized diagnostic criteria. Circulation 2000; 101(17): 2118-21.
[46] Vasan RS, Benjamin EJ. Diastolic heart failure--no time to relax. N Engl J Med 2001; 344(1): 56-9.

[47] Weber KT. Cardiac interstitium in health and disease: the fibrillar collagen network. J Am Coll Cardiol 1989; 13(7): 1637-52.

[48] Kim S, Iwao H. Molecular and cellular mechanisms of angiotensin II-mediated cardiovascular and renal diseases. Pharmacol Rev 2000; 52(1): 11-34.

[49] Bernardi M, Di Marco C, Trevisani F, et al. Renal sodium retention during upright posture in preascitic cirrhosis. Gastroenterology 1993; 105(1): 188-93.

[50] Pozzi M, Grassi G, Redaelli E, et al. Patterns of regional sympathetic nerve traffic in preascitic and ascitic cirrhosis. Hepatology 2001; 34(6): 1113-8.

[51] Morali GA, Floras JS, Legault L, Tobe S, Skorecki KL, Blendis LM. Muscle sympathetic nerve activity and renal responsiveness to atrial natriuretic factor during the development of hepatic ascites. Am J Med 1991; 91(4): 383-92.

[52] Stanton HC, Brenner G, Mayfield ED, Jr. Studies on isoproterenolinduced cardiomegaly in rats. Am Heart J 1969; 77(1): 72-80.

[53] Yuda S, Short L, Leano R, Marwick TH. Myocardial abnormalities in hypertensive patients with normal and abnormal left ventricular filling: a study of ultrasound tissue characterization and strain. Clin Sci (Lond) 2002; 103(3): 283-93.

[54] Lythall DA, Gibson DG, Kushwaha SS, Norell MS, Mitchell AG, Ilsley CJ. Changes in myocardial echo amplitude during reversible ischaemia in humans. Br Heart J 1992; 67(5): 368-76.

[55] Naito J, Masuyama T, Tanouchi J, et al. Analysis of transmural trend of myocardial integrated ultrasound backscatter for differentiation of hypertrophic cardiomyopathy and ventricular hypertrophy due to hypertension. J Am Coll Cardiol 1994; 24(2): 517-24.

[56] Di BV, Pedrinelli R, Giorgi D, et al. Ultrasonic myocardial textural parameters and midwall left ventricular mechanics in essential arterial hypertension. J Hum Hypertens 2000; 14(1): 9-16.

[57] Hoyt RM, Skorton DJ, Collins SM, Melton HE, Jr. Ultrasonic backscatter and collagen in normal ventricular myocardium. Circulation 1984; 69(4): 775-82.

[58] Matsumori A, Matoba Y, Nishio R, Shioi T, Ono K, Sasayama S. Detection of hepatitis $\mathrm{C}$ virus RNA from the heart of patients with hypertrophic cardiomyopathy. Biochem Biophys Res Commun 1996; 222(3): 678-82.

[59] Teragaki M, Nishiguchi S, Takeuchi K, Yoshiyama M, Akioka K, Yoshikawa J. Prevalence of hepatitis $\mathrm{C}$ virus infection among patients with hypertrophic cardiomyopathy. Heart Vessels 2003; 18(4): 167-70

[60] Dalekos GN, Achenbach K, Christodoulou D, et al. Idiopathic dilated cardiomyopathy: lack of association with hepatitis $\mathrm{C}$ virus infection. Heart 1998; 80(3): 270-5.

[61] Prati D, Poli F, Farma E, et al. Multicenter study on hepatitis C virus infection in patients with dilated cardiomyopathy. North Italy Transplant Program (NITP). J Med Virol 1999; 58(2): 116-20.

[62] Yan FM, Chen AS, Hao F, et al. Hepatitis C virus may infect extrahepatic tissues in patients with hepatitis C. World J Gastroenterol 2000; 6(6): 805-11.

[63] Pozzi M, Ratti L, Guidi C, Milanese M, Mancia G. Potential therapeutic targets in cirrhotic cardiomyopathy. Cardiovasc Hematol Disord Drug Targets 2007; 7(1): 21-6.

[64] Gaskari SA, Honar H, Lee SS. Therapy insight: Cirrhotic cardiomyopathy. Nat Clin Pract Gastroenterol Hepatol 2006; 3(6): 32937.

[65] Schepke M, Werner E, Biecker E, et al. Hemodynamic effects of the angiotensin II receptor antagonist irbesartan in patients with cirrhosis and portal hypertension. Gastroenterology 2001; 121(2): 389-95. 